\title{
How do people differentiate between jobs: and how do they define a good job?
}

\author{
Wendy Jones*, Roger Haslam and Cheryl Haslam \\ Loughborough Design School, Loughborough University, Ashby Road, Loughborough, LE11 3TU, UK.
}

\begin{abstract}
Employed individuals from a range of jobs $(\mathrm{n}=18)$ were interviewed using a repertory grid technique, to explore the criteria they used to distinguish between different jobs. The concepts of 'a good job' and 'a job good for health' were also discussed. Interactions with others and the job itself were the most commonly used criteria and were also the most common features of a 'good job'. Pay and security were mentioned frequently but were less important when comparing jobs and when defining a 'good job'. Physical activity was rarely associated by interviewees with a 'good job' but was frequently associated with a 'job good for health'. A comprehensive definition of a 'good job' needs to take all these factors into account.
\end{abstract}

Keywords: job quality; good job; repertory grid; health

\section{Introduction}

The World Health Organization, the International Labor Organization and the European Union all have ongoing programmes to improve work quality and ensure that employment contributes to good health. Individual countries including Austria, Belgium and the Czech Republic have programmes to assess and improve job quality, and there is involvement from trade unions in many countries including Germany and Sweden. Within the United Kingdom, the Government has a Health, Work and Wellbeing agenda aimed at promoting the health benefits of employment.

This interest in job quality arises from the impact of work on health. Factors such as job strain [5], effort reward imbalance [15] and poor pay and security [4] have all shown associations with poor or deteriorating health. There is also evidence to show that particular physical demands can have an adverse effect on health $[11,9]$ as well as certain shift patterns [17] and working relationships [8]. However, the topic is a complex one due to the interaction between different factors and the different ways in which many of these factors can be assessed. In addition, identifying the factors which can make a job bad for health, does not necessarily tell us which features need to be present for a job to be good.

A systematic review of the published literature by Waddell and Burton [18] concluded that work is generally good for health but that the nature and quality of work is important. They identified that there is currently, "...insufficient evidence to define the physical and psychological characteristics of jobs and workplace that are 'good' for health"

\section{Method}

Exploratory interviews were conducted with 18 employed individuals. They had a range of ages and employment backgrounds to broadly represent the UK working population, it was not intended to explore difference between different subsections within that population.

The aim was to explore the criteria interviewees used when assessing job quality i.e. what are the differences they see when they look at a range of jobs. The range of jobs used in each discussion was specific to that individual and included their own job, jobs they had done before and jobs they would particularly like or not like to do. Interviewees were also asked open questions about the attributes which

${ }^{*}$ Corresponding author. E-mail: w.jones2@lboro.ac.uk +44 1509228485. 
contributed to 'a good job' and a job which is ' $g o o d$ for health'.

The interviews used a repertory grid design. This is an interview technique that has developed from George Kelly's Personal Construct Theory in clinical psychology [6]. It has specific strengths in its ability to identify interviewees' underlying beliefs, encouraging them to verbalise constructs, "which would otherwise remain hidden" [1]. It also introduces a minimum of interviewer bias [2].

\section{Results}

The differences and similarities interviewees described between jobs were subject to content analysis to identify the most common themes. The three topics mentioned most frequently were 'interactions with others', 'pay or security' and 'the job itself.' This is shown in figure 1. Interviewees also talked about the following (listed in descending order of frequency)
- Responsibility

- Physical demands

- Physical factors (indoors/outdoors, health and safety

- Emotional outcomes (stress; influencing people)

- Working hours

- Autonomy

- Recognition

- Job requirements (level of training needed)

- Job choice reasons (e.g. career choice or necessity)

'Interactions with others' covered examples of poor working relationships with colleagues or managers, the benefits of team working and the advantages and disadvantages of working with the public. This theme was mentioned at some point by all interviewees. It was also an important factor when comparing different jobs and the most common prerequisite for a 'good job'.

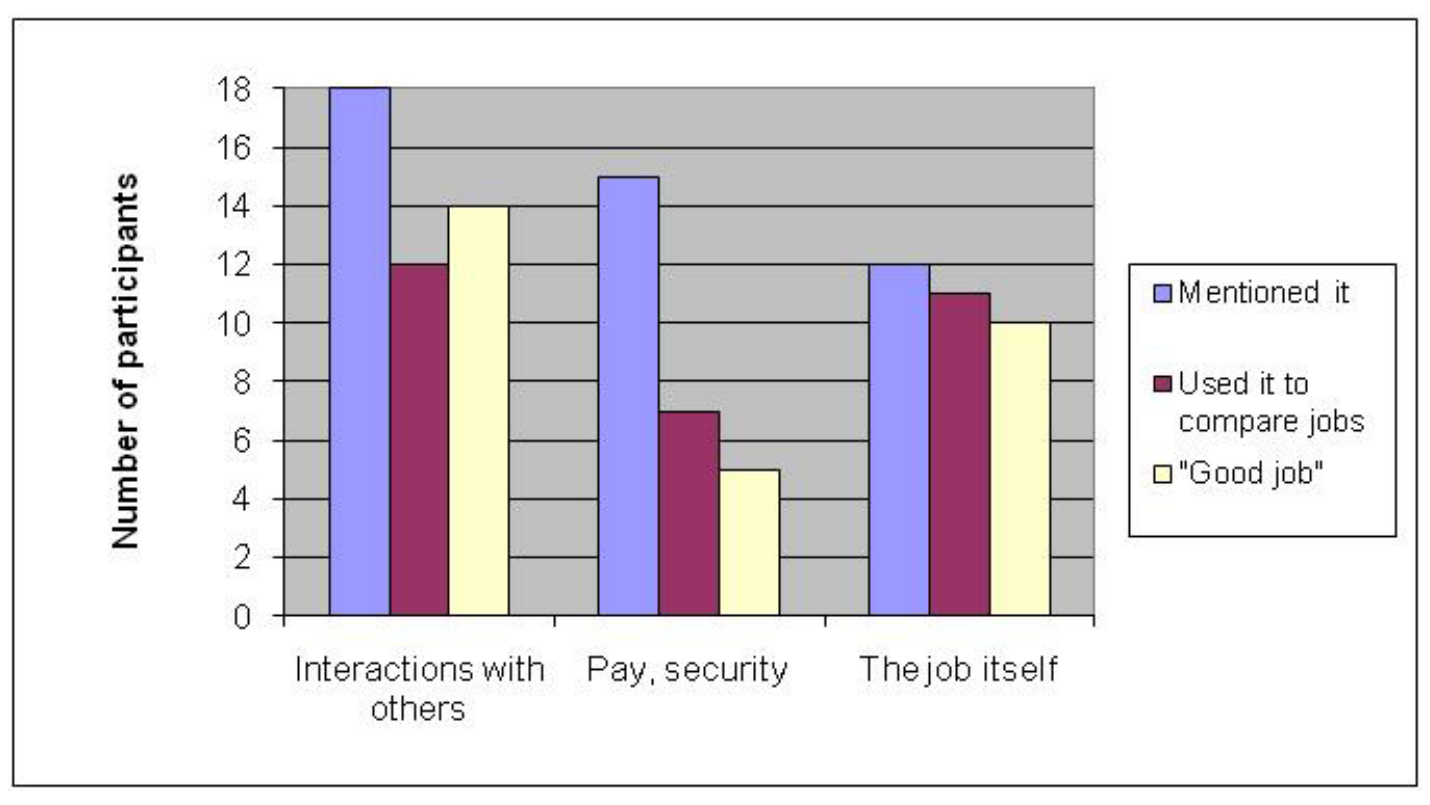

Figure 1

Themes mentioned most frequently in interviews 
'The job itself' was discussed predominantly using ideas around creativity vs rigidity and variety vs routine. It was the second most frequently mentioned attribute of a good job. Almost all interviewees favoured creative, varied work over the routine. When participants were asked to identity a job which they had most disliked or one which they would not wish to do, almost half of them identified a job which they considered intolerably boring.

'Pay' or 'security' was mentioned by 15 interviewees at some point during the interview. However, this included four interviewees who specifically stated that money was not the key driver in job choice. Only seven interviewees mentioned pay or security when looking at the differences between jobs. Only five said that pay was an important aspect of a good job.

The features associated with a job which is good for health were very different from those associated with a good job. 'Low stress' was identified as beneficial for health (although interviewees had different views on what constituted stress). 'Physical activity' was also mentioned by eleven interviewees as important to good health, but only one said it would be important for a good job.

\section{Discussion}

Interviewees showed an overall preference for jobs which were creative or varied. In the UK, there has been a decline in manufacturing jobs over the last forty years, but work in data processing, and telephone call handling have increased and may be similarly lacking in diversity. There is a challenge for employers in ensuring that such jobs can be considered as good jobs. It is unclear to what extent improving other aspects of employment, for example by facilitating good working relationships and skilled management, will compensate for unsatisfying job content.

It is of importance that we understand this better. Low value ascribed by society to certain types of work contributes to low status of such jobs and those who do them, this may be a factor in the health gradient identified in the Whitehall II studies and explored at length by Michael Marmot [7].

Pay, autonomy, recognition and working hourswere mentioned less frequently by interviewees in this study than may be expected from the literature. One possible explanation is that such features need to be present to ensure that a job is not bad, but by themselves are insufficient to allow a job to be considered as good. This would be predicted by Herzberg's motivation-hygiene theory [3]. Although this model is one which has generally fallen out of favour [14] its basic premise fits in line with the widely accepted view that wellbeing is more than just the absence of disease; and thus that a good job is more than the opposite of a bad one.

Although interviewees didn't consider physical activity important to a good job, they did recognise its importance for health. This is supported in the literature which shows the negative impact of sedentary lifestyles on health [e.g.10]. Incorporating activity into jobs is notoriously difficult [16], and likely to remain so, particularly if, as this small study suggests, most employees don't associate physical activity with high quality employment. However, given the significance of the health impact of inactivity, it is important that this factor is also built into any assessment of what constitutes a good job.

In conclusion, any definition of a good job needs to take account of job content and relationships in addition to those factors commonly associated with health effects such as pay levels and job strain. It also needs to consider the balance between physical activities which are potentially harmful due to high demands, and the risks which arise from inactivity.

\section{Limitations}

The study described has a small sample size which limits generalisation of the findings. It is possible that the sample group were not truly representative of the UK working population and this may explain the relatively low significance ascribed to factors such as pay, job security and autonomy in comparison to those found in the literature [e.g. 13, 12]. It is also possible that the sample group were unusual in their preference for interesting and varied work and that many employees are less concerned about such intrinsic factors. It is of particular note that a number of interviewees said they could not contemplate working in a production line environment, but knew a number of people who would be perfectly happy with that. It is also likely that the open nature of the repertory grid interviews encouraged interviewees to focus on the theoretical aspects and content of job roles rather than the practical aspects of specific jobs. 


\section{References}

[1] Easterby-Smith, M., Thorpe, R. \& Holman, D. 1996, "Using repertory grids in management", Journal of European Industrial Training, vol. 20, no. 3, pp. 3-30.

[2] Fransella, F., Bell, R. \& Bannister, D. 2004, A Manual for Repertory Grid Technique, 2nd edn, John Wiley \& Sons Ltd, Chichester.

[3] Herzberg, F., Mausner, B. \& Snyderman, B. 1959, The Motivation to Work, John Wiley and sons, New York.

[4] Kalleberg, A.L., Reskin, B.F. \& Hudson, K. 2000, "Bad Jobs in America: Standard and Nonstandard Employment Relations and Job Quality in the United States", American Sociological Review, vol. 65, no. 2, pp. 256-278.

[5] Karasek, R. 1979, "Job Demands, Job Decision Latitude, and Mental Strain: Implications for Job Redesign", Administrative Science Quarterly, vol. 24, no. 2, pp. 285308.

[6] Kelly, G. 1955, The psychology of personal constructs, Norton, New York (reprinted by Routledge, London).

[7] Marmot, M. 2004, Status Syndrome, Bloomsbury, London.

[8] Netterstrom, B., Conrad, N., Bech, P., Fink, P., Olsen, O., Rugulies, R. \& Stansfeld, S. 2008, "The relation between work-related psychosocial factors and the development of depression", Epidemiologic reviews, vol. 30, pp. 118-132.

[9] Nordander, C., Ohlsson, K., Akesson, I., Arvidsson, I., Balogh, I., Hansson, G., Stromberg, U., Rittner, R. \& Skerfving, S. 2009, "Risk of Musculoskeletal Disorders among Females and Males in Repetitive/Constrained Work", Ergonomics, vol. 52, no. 10, pp. 1226-1239.

[10]Patel, A.V., Bernstein, L., Deka, A., Feigelson, H.S., Campbell, P.T., Gapstur, S.M., Colditz, G.A. \& Thun, M.J.
2010, "Leisure Time Spent Sitting in Relation to Total Mortality in a Prospective Cohort of US Adults", American Journal of Epidemiology, vol. 172, no. 4, pp. 419-429.

[11]Punnett, L. \& Wegman, D.H. 2004, "Work-related musculoskeletal disorders: the epidemiologic evidence and the debate", Journal of Electromyography and Kinesiology, vol. 14 , no. 1 , pp. 13-23.

[12]Rose, M. 2007, "Why so fed up and footloose in IT? Spelling out the associations between occupation and overall job satisfaction shown by WERS 2004", Industrial Relations Journal, vol. 38, no. 4, pp. 356-384.

[13]Rose, M. 2003, "Good Deal, Bad Deal? Job Satisfaction in Occupations", Work, Employment \& Society, vol. 17, no. 3, pp. 503-530.

[14] Sachau, D.A. 2007, "Resurrecting the Motivation-Hygiene Theory: Herzberg and the Positive Psychology Movement", Human Resource Development Review, vol. 6, no. 4, pp. 377-393.

[15] Siegrist, J. 1996, "Adverse health effects of high-effort/lowreward conditions", Journal of occupational health psychology, vol. 1, no. 1, pp. 27-41.

[16] Straker, L. \& Mathiassen, S.E. 2009, "Increased physical work loads in modern work - a necessity for better health and performance?", Ergonomics, vol. 52, no. 10, pp. 1215.

[17] Swerdlow, A. 2003, , Shift work and breast cancer: a critical review of the epidemiological evidence: RR 132 [Homepage of HSE], [Online]. Available: http://www.hse.gov.uk/research/rrpdf/rr132.pdf [2011, July 29].

[18] Waddell, G. \& Burton, A.K. 2006, Is work good for your health and wellbeing?, The Stationary Office, London. 